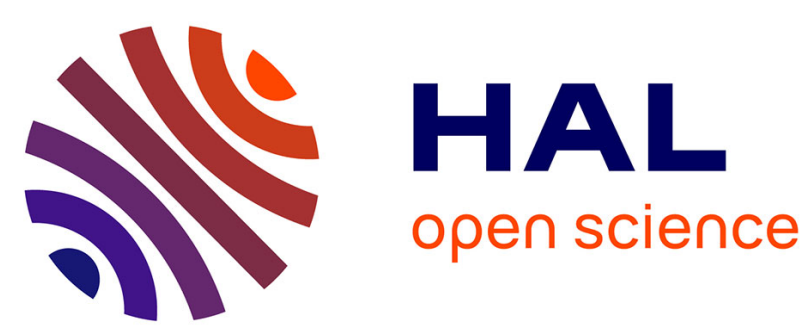

\title{
ANALYSIS OF STUDENTS' BEHAVIOR REGARDING THE USE OF OPEN SOURCE REMOTE LABORATORIES
}

C Lavayssière, B Larroque, Franck Luthon

\section{- To cite this version:}

C Lavayssière, B Larroque, Franck Luthon. ANALYSIS OF STUDENTS' BEHAVIOR REGARDING THE USE OF OPEN SOURCE REMOTE LABORATORIES. 13th annual International Conference on Education and New Learning Technologies (EDULEARN21), Jul 2021, Mallorca (virtual ), Spain. hal-03230065

\section{HAL Id: hal-03230065 \\ https://hal.science/hal-03230065}

Submitted on 19 May 2021

HAL is a multi-disciplinary open access archive for the deposit and dissemination of scientific research documents, whether they are published or not. The documents may come from teaching and research institutions in France or abroad, or from public or private research centers.
L'archive ouverte pluridisciplinaire $\mathbf{H A L}$, est destinée au dépôt et à la diffusion de documents scientifiques de niveau recherche, publiés ou non, émanant des établissements d'enseignement et de recherche français ou étrangers, des laboratoires publics ou privés. 


\title{
ANALYSIS OF STUDENTS' BEHAVIOR REGARDING THE USE OF OPEN SOURCE REMOTE LABORATORIES
}

\author{
C. Lavayssière ${ }^{1}$, B. Larroque ${ }^{2}$, F. Luthon ${ }^{1}$ \\ ${ }^{1}$ Universite de Pau et des Pays de l'Adour, E2S UPPA, LIUPPA, Anglet, France \\ ${ }^{2}$ Universite de Pau et des Pays de l'Adour, E2S UPPA, SIAME, Anglet, France
}

\begin{abstract}
As a result of the global health crisis since the beginning of 2020 , the decisions taken by governments have led to a sudden increase in distance learning. This situation forces students to be isolated during their learning and complicates their access to practice in technical fields. Laborem platform, which has been developed and regularly evaluated since 2011, allows students of the University Institute of Technology in Bayonne, France, (IUT de Bayonne) to do practical works in electronics remotely. Teachers can easily create web interfaces connected to multiple instruments. Since 2017, a new platform is used with open source hardware and software. To be attractive, both on the teacher and student side, the remote platform must be simple to set up and easy to access via a web client. Here, by varying the access schedule and having students work alone or in pairs, different use cases of an open source remote laboratory are evaluated and compared.
\end{abstract}

Keywords: e-learning, student motivation, lab work, online education, remote laboratories, SCADA.

\section{INTRODUCTION}

Distance learning is growing easier and faster with the pandemic situation all over the world. In this context, universities have chosen to offer e-learning solutions to students. To answer this issue for practical works, it appears decisive to use robust and easy-to-set-up software and hardware solutions.

It seems essential to provide to the teachers a simple, reliable and versatile tool. Since 2011 a remote laboratory called Laborem has been developed and used [1]. Compared to other remote laboratories, Laborem aims to provide teachers with a simple tool to connect their hands-on equipment and to quickly create a student-friendly interface. Laborem is not dedicated to one scientific field or one type of instrument. The current version is using only open source software running on a single-board computer. A motherboard has been developed allowing the student to choose among sixteen groups of electrical circuits (plugs) to be studied. The teacher can change the plugs as well as the input/output connections to the instruments via standard sockets. All the hardware developed was made as open-source hardware.

In order to evaluate the best possible scenario for the students, different ways to access the laboratory will be analysed and compared.

\section{METHODOLOGY}

\subsection{Technical implementation}

To meet the growing need for practical work in higher education, an open source software and hardware solution has been developed. It is easy to use for students and teachers, adaptable to different scenarios and easily replicable.

The architecture of Laborem is shown in Fig. 1. A Rapsberry Pi is used as a server which contains the open source software. The motherboard has different input/output ports to connect all the equipment required for practical work, and to connect to other elements (robotic arm used to pick up and move components, function generator, multimeter, oscilloscope, Raspberry $\mathrm{Pi}$ ).

Moving to open source hardware and software since 2018 allowed to easily duplicate the system and increased its scalability [2]. This change requires respecting a virtuous development cycle common to the industry: development, testing, production, feedback. The goal is to reduce the number of problems during production's step. 


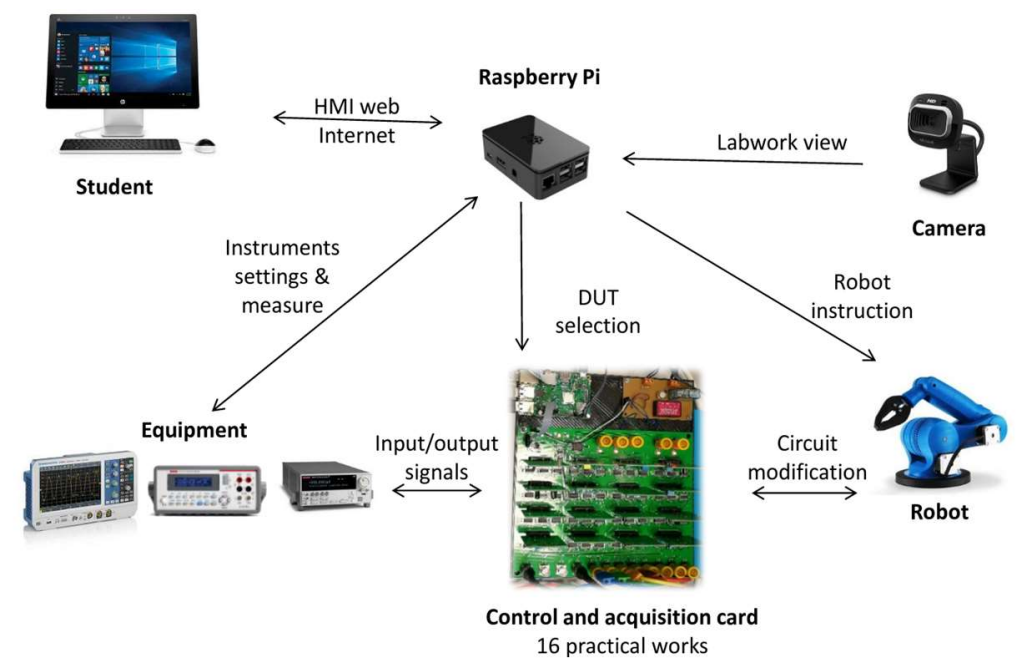

Figure 1. Overview of Laborem system architecture (where DUT means Device Under Test, and HMI means Human Machine Interface).

\subsubsection{Hardware implementation}

The motherboard, the circuits of the electronic practical work, the power supply board and the plastic case were developed and assembled into a so-called "Laborem Box" at the IUT de Bayonne. (Fig. 2).

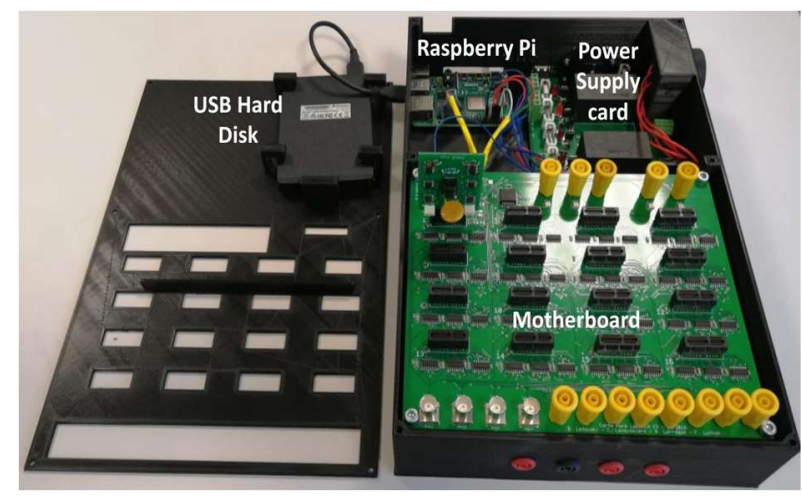

Figure 2. The Laborem Box.

These circuits cover all the lessons of first and second year of electronics for our undergraduate students.

They can be grouped on a single PCB (printed-circuit board) that is plugged on a motherboard accepting up to 16 plugs (Fig. 3). The motherboard allows to choose the plug as well as the sub-circuit by controling switches into the plug. By this way, the system is currently able to implement up to 64 simultaneously accessible circuits ( 4 circuits by plug).

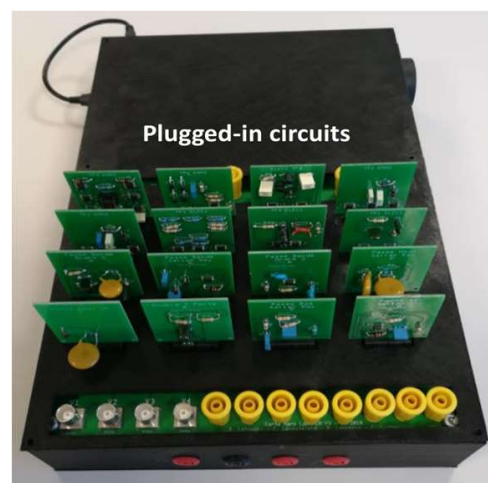

Figure 3. The motherboard in its box with 16 plugs. 


\subsubsection{Software implementation}

The software used by Laborem, presented in ICERI 2019 [3], is based on a python Supervisory Control and Data Acquisition (SCADA) software, named PyScada [4] [5], whose web interface offers a high level environment to provide real time access to practical works at IUT de Bayonne. The PyScada platform is composed of an administration interface (backend) used by the teacher to define the instruments and variables as well as to build the student interface (frontend).

Firstly, PyScada allows, via its intuitive administration interface, to add devices (motherboard, function generator, oscilloscope, multimeter, robot, camera...), connected to the Raspberry Pi via various communication protocols (modbus, smbus, onewire, visa, webservice...), to configure the input (acquisition) or output (configuration) variables. Then, in a second time, it makes easy to create a rich and interactive web HMI to interact remotely with the connected system (graphics, text, buttons, live video, information on the system, previous values, process representation...).

In this way, Laborem is not only a turnkey tool for remote electronics practical work, but a remote laboratory building system adaptable to any remote-control system (Fig.4).

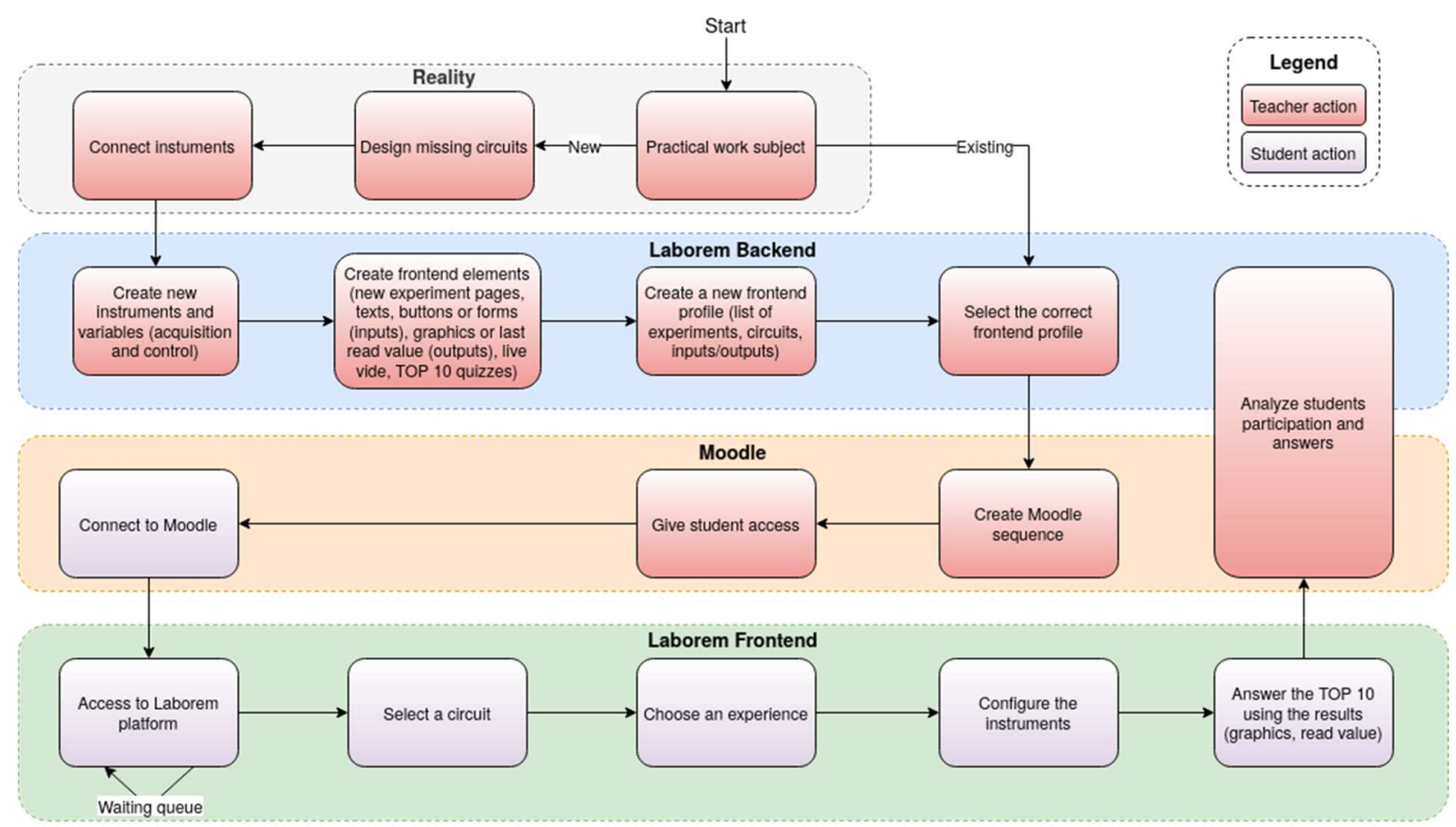

Figure 4. Laborem remote laboratory process.

For example, in the backend interface (Fig. 5), the teacher can adapt the frontend to the needs of the student or the course by adding new instruments, create several HMI profiles, monitor his or her learning via dynamic quizzes and set up video feedback. This is done without any line of code.

To set up a course, the teacher selects the pre-configured course and the desired HMI profile (which corresponds to the type of experiments proposed, e.g. study of the frequency response, spectral analysis...). The interface indicates the plugs to be connected and displays the wiring to be done between the motherboard and the instruments (oscilloscope, function generator, multimeter).

All student activities involved for remote experiments, such as questions and settings, are stored in the administration interface. 


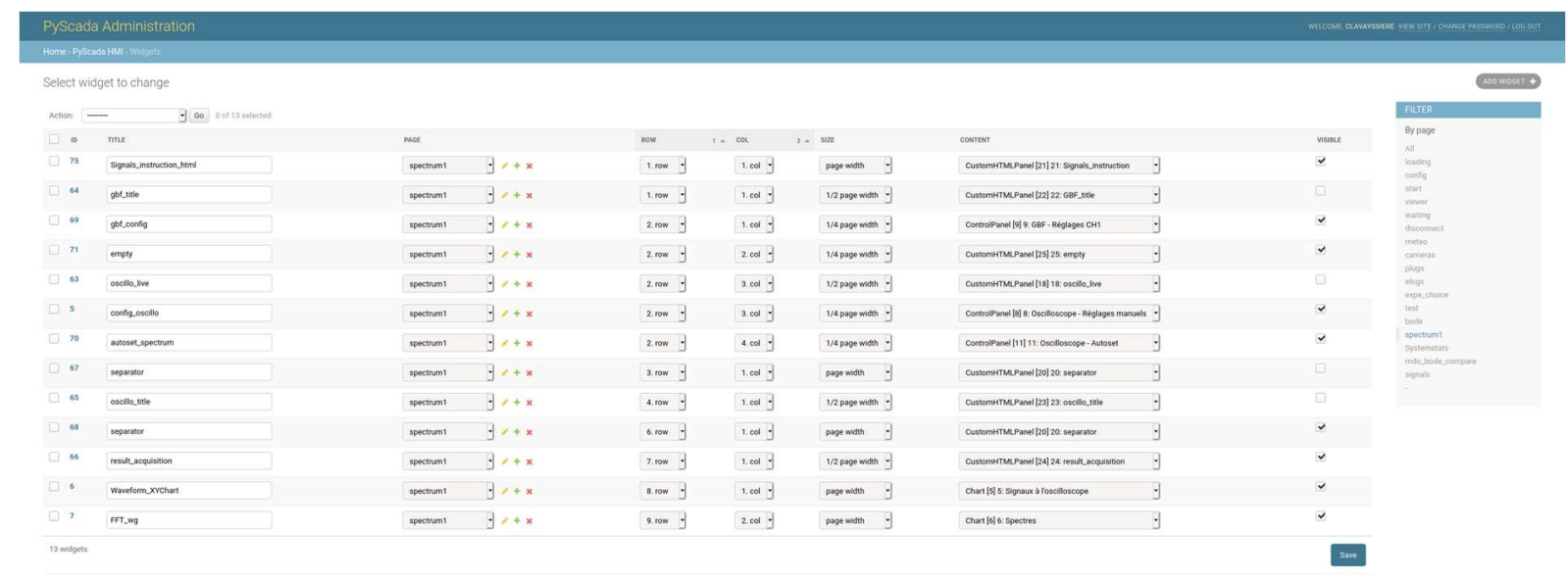

Figure 5. The administration interface of PyScada. Content management of the "Bode diagram" page (see Fig. 6).

The user interface contains a home page, a page for selecting the circuit to be studied and a page for each experiment. On the page dedicated to the study of Bode diagrams (Fig. 6), the user can fill in a form to configure the experiment (on the right side), as well as see the consecutive results displayed (here in two graphs) on left side. The navigation bar at the top gives an access to the list of users in the waiting queue, as well as to the questions and results for each circuit. Each student can participate and compare immediately himself with his or her classmates' scores in a list called TOP 10.

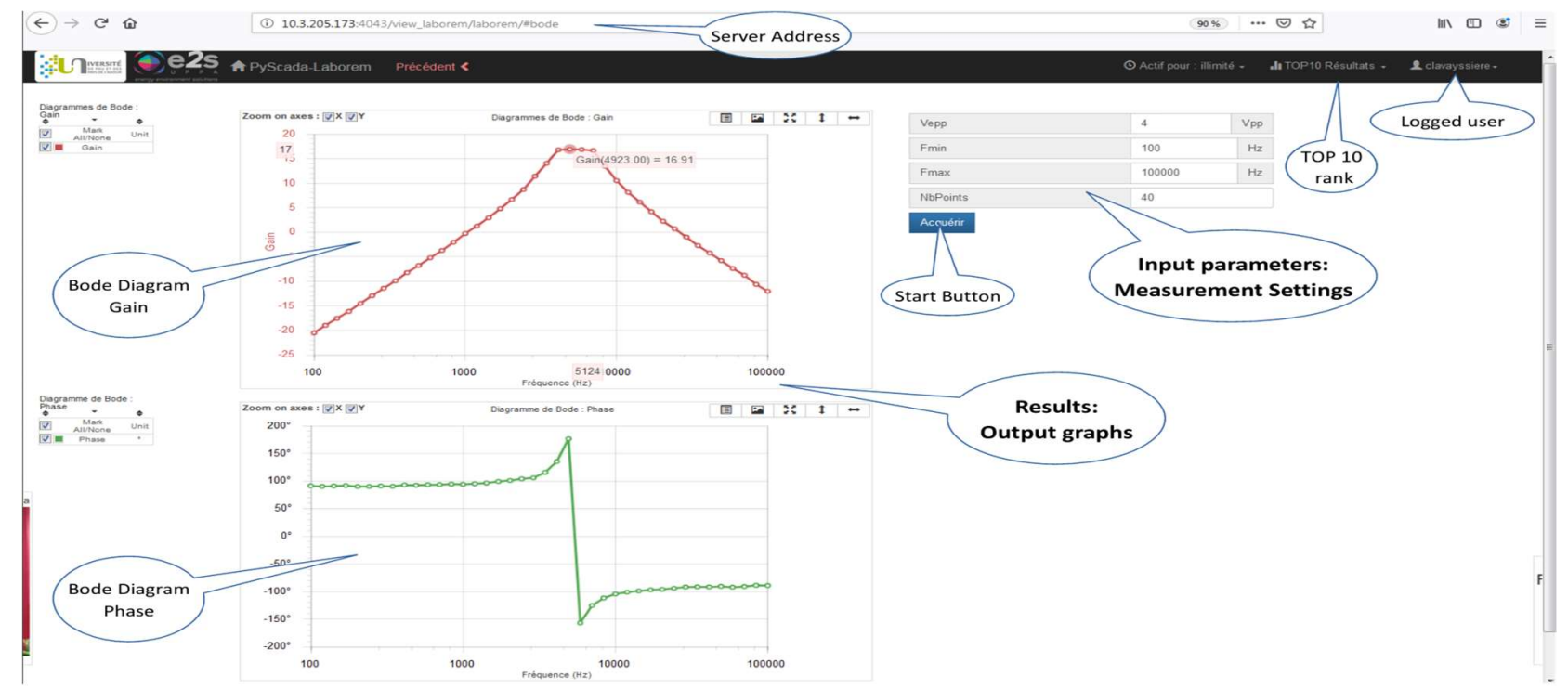

Figure 6. The student interface of Laborem. Bode diagram of a second order band pass active filter.

\subsection{Scenarios evaluation and comparison}

The purpose of this part is to define the technical conclusions in regards to the pedagogical needs observed in this field experience.

\subsubsection{Ecosystem integration}

Since Laborem platform is integrated into a Learning Management System (LMS) named Moodle, accesses and results of each user can be compared. Laborem is part of a hybrid scenario where students have completed a first sequence of the course by a hands-on activity, followed by a distance learning session. 
For the second sequence, the typical scenario (shown in Fig. 7) consists of a video presentation plus an online course (step 1), a pre-requisite test plus a formative test (step 2), two remote practical works with three levels of difficulty (beginner, intermediate, or advanced) using the Laborem platform (steps 3 and 4), and a final summative test with the uploading of a report plus a satisfaction survey (step 5).

Students could exchange with each other or with teachers using an online forum on the Moodle platform.

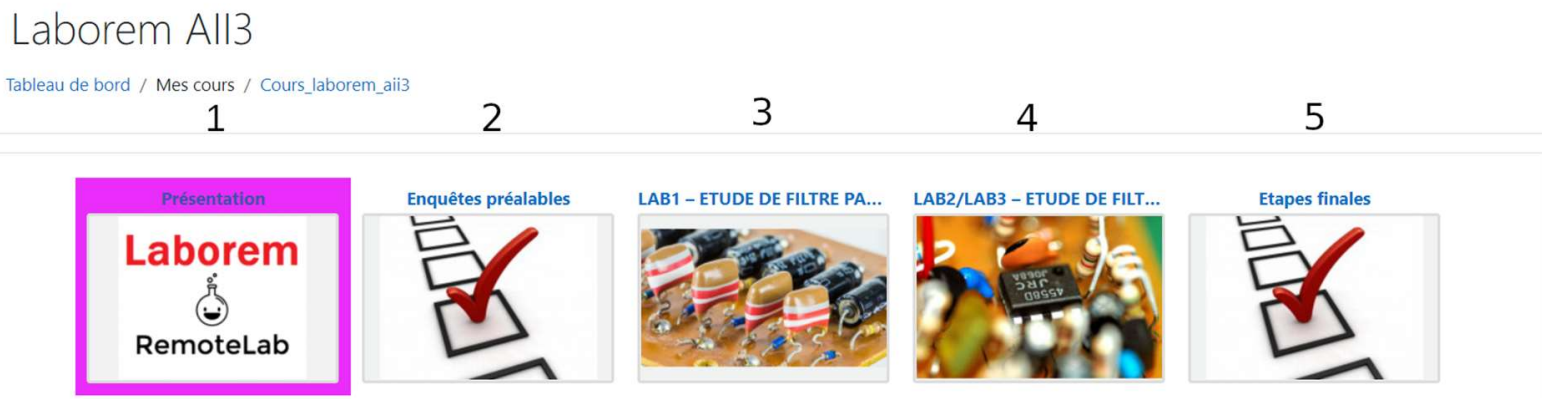

Figure 7. View of the 5-step sequence online in Moodle.

\subsubsection{Three remote learning approaches}

The class studied this year on the Laborem platform was composed of 42 first-year undergraduate students from the IUT de Bayonne. To determine Laborem's effectiveness and satisfaction, the class of students was divided into three groups to compare different usage scenarios.

Scheduling and queue management for remote labs has a significant impact on wait times and resource utilization levels [4]. Pair learning in programming has shown its benefits in terms of quality of work produced and productivity [5] [6]. It tends to improve enjoyment, increase student confidence, reduce workload, improve course completion rates, increase assignment submission rates, and improve exam results.

In order to analyze the influence of these criteria in the context of remote laboratories, the influence of time management and pair learning is studied hereafter. By modifying two criteria, namely individual or paired passage, and free or restricted temporal access, the use (frequency, duration, regularity), the results (completion, grades) and the satisfaction (feelings, expectations) of each group are compared.

The first group had 14 days fully open to realize the practical work subject using Moodle and Laborem. They had access to the platform at any time.

The second group had one day reserved for each student plus 7 days (March 27, 28 and April 3, 4, 9, $10,11)$ of free access.

The last group was formed by pairs who had one day reserved for each pair, plus 6 days (April 17, 18, $21,22,23,24)$ of free access.

\subsubsection{Scenarios analysis}

\subsubsection{Access frequency, duration and regularity}

The students had to do a practical work on active and passive filters. They had to study the frequency response of the filters with the use of Bode diagrams (gain and phase) as well as to characterize the temporal response and the spectrum of the signals. In Figure 8, one can see on the left axis the stacked amount of experiments performed and on the right axis the amount of TOP 10 responses.

As can be deduced from Fig. 8 and Table 1, for the first group in totally open access, the first half of the time was never used and $67 \%$ of the experiments launched were completed during the last day. For the second group which was in free access $12.5 \%$ of the time, $85 \%$ of the launched experiments were 
realized on a free time period. For the third group that worked in pairs, $17 \%$ of the experiments launched were realized during a free access ( $14.3 \%$ of the access time).

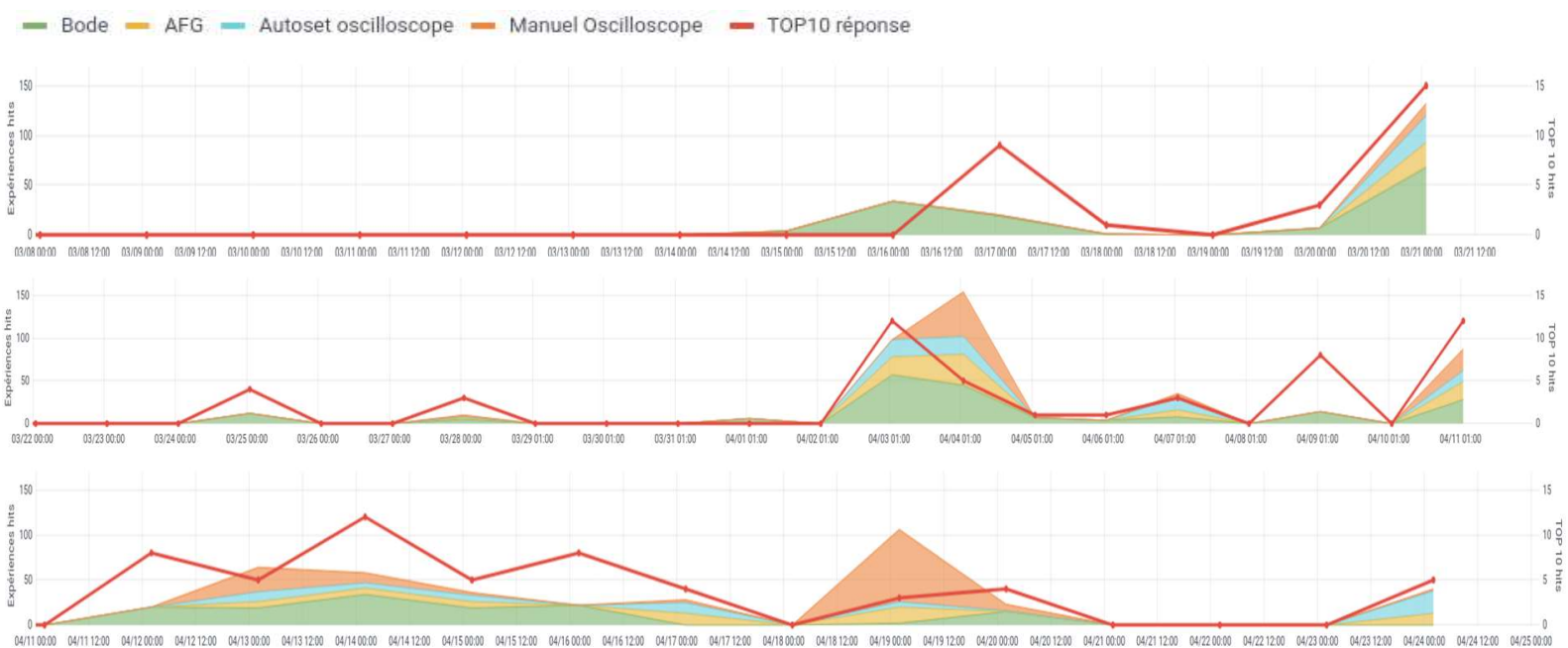

Figure 8. First (top), second (middle) and third (bottom) groups number of experiments performed (left stacked $y$-axis : bode diagram in green, AFG configuration in yellow, oscilloscope autoset and manual configuration in blue and orange) and responses to the TOP 10 (right $y$-axis in red).

Table 1. Student and Pair access and participation.

\begin{tabular}{l|c|c|c|}
\hline \hline & Group 1 & Group 2 & Group 3 \\
\hline $\begin{array}{l}\text { Free time ratio for } \\
\text { the student or pair }\end{array}$ & $100 \%$ & $12.5 \%$ & $14.3 \%$ \\
\hline $\begin{array}{l}\text { Ratio of experiences } \\
\text { performed on free } \\
\text { time }\end{array}$ & $100 \%$ & $85 \%$ & $17 \%$ \\
\hline $\begin{array}{l}\text { Ratio of experiences } \\
\text { performed of the } \\
\text { most active day }\end{array}$ & $67 \%^{*}$ & $36 \%^{*}$ & $27 \%$ \\
\hline
\end{tabular}

* The most active day of group 1 and 2 was during a free access time.

Fig. 9 shows that the amount of experiments performed and answers given to the TOP10 approximately doubles between group 1 and 2 , and between group 2 and 3 . While the ratio of experiments performed on the most active day is divided by almost 2 between group 1 and 2, and the ratio of experiments performed on free time is divided by 5 between group 2 and 3 (Table 1).
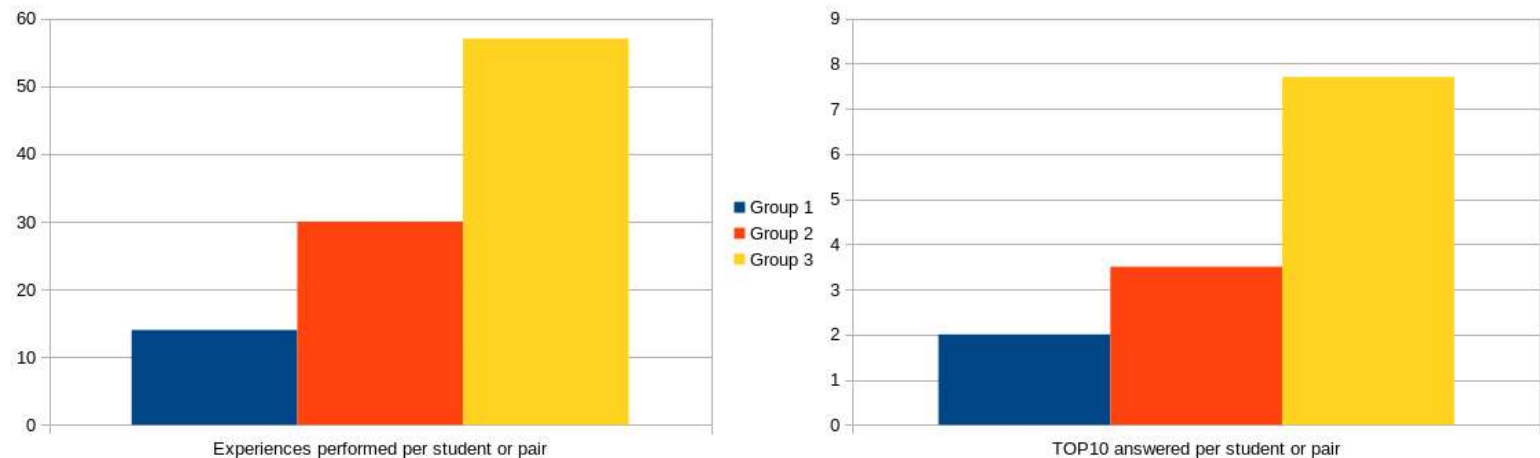

Figure 9. Total of experiences (left) and TOP 10 answers (right) per student or pair. 
Students working individually (group 1 and 2) mainly use the last available day. In order to respond to this time management, a remote lab must be robust to a large number of simultaneous connections or impose a schedule (no free time) in order to foresee the maximum number of simultaneous connections.

\subsubsection{Student motivation}

An anonymous a priori and a posteriory survey based on students' intrinsic and extrinsic motivation over the whole class is presented with the average values which are compared to previous years in Table 2. This study result is in the average range of the years previously compared (no significant difference).

Table 2. Student motivation (on a 5-point Likert scale)

\begin{tabular}{l|c|c|c|c|}
\hline \hline Year & \multicolumn{2}{|c|}{ Intrinsic } & \multicolumn{2}{c|}{ Extrinsic } \\
\hline Pre-Inquiry & Mean & Incr. & Mean & Incr. \\
2011 (29 stud.) & 3.73 & & 2.06 & \\
2012 (22 stud.) & 3.89 & & 1.95 & \\
2013 (25 stud.) & 4.18 & & 2.42 & \\
2021 (42 stud.) & 3.94 & -0.24 & 2.46 & +0.04 \\
\hline Post-Inquiry & Mean & Incr. & Mean & Incr. \\
2012 (22 stud.) & 3.1 & & 2.55 & \\
2013 (25 stud.) & 3.5 & & 3.1 & \\
2021 (42 stud.) & 3,17 & $-0,33$ & 2,85 & $-0,25$ \\
\hline
\end{tabular}

According to Table 3, the most important thing for them is to improve their skills (4.4/5) far ahead of the importance of looking smart compared to others (1.7/5). Perhaps the isolation of doing the work remotely explains this result.

Table 3. Sample of questions and scoring from anonymous questionnaires a priori or a posteriori (on a 5-point Likert scale)

\begin{tabular}{l|l|l|l|}
\hline \hline & Survey & Question & Score \\
\hline \multirow{2}{*}{ A priori } & \multirow{2}{*}{ Motivation } & Improve their skills & 4.4 \\
\cline { 3 - 4 } & & Looking smart compared to others & 1.7 \\
\hline \multirow{2}{*}{ A posteriori } & \multirow{2}{*}{ Psychological } & Motivation for this distance learning activity & 2.1 \\
\cline { 3 - 4 } & & Preference for face-to-face practical work & 4.5 \\
\cline { 3 - 4 } & & Desire to succeed in their learning path & 4.3 \\
\hline
\end{tabular}

This lack of motivation is reflected in the students' reports where some did not complete the last part of the assignment.

In spite of the lack of motivation for this distance learning activity (2.1/5), as opposed to the preference for face-to-face practical work (4.5/5) shown by the psychological post-survey (Table 3 ), participation was good. This probably comes from the desire to succeed in their learning path being high (4.3/5).

In order to maintain the motivation (which is the usual job of a teacher when present) during a remote work of several hours, it seems necessary to have control tools (detection by the remote laboratory, warning of the teacher) and reinforcement or reward (avoid the abandonment, the cheating, solicit the student, incite him by the game...). 


\subsubsection{Platform evaluation}

Whatever the various surveys, namely psychological, detailed (70 questions) or overall survey (10 questions), the need for collaborative or paired work stands out (Table 4).

Table 4. Sample of questions and scoring about collaborative work from anonymous questionnaires a priori or a posteriori (on a 5-point Likert scale)

\begin{tabular}{l|l|l|l|}
\hline \hline & Survey type & Question & Score \\
\hline \multirow{2}{*}{ A posteriori } & Psychological & Need for collaborative work with my peers & 3.8 \\
\cline { 2 - 4 } & Detailed & Need to collaborate with my colleagues & 3.6 \\
\cline { 3 - 4 } & Preferred to work in pairs & 4.4 \\
\cline { 2 - 4 } & Overall & $\begin{array}{l}\text { Interest in collaborative work (with a partner or a } \\
\text { tutor) }\end{array}$ & 3.8 \\
\hline
\end{tabular}

In order to deepen the interest of collaboration for remote practical work, it seems necessary to have reliable tools that allow pair work (video, screen sharing, remote control, chat) and to measure and track the use of these tools.

\subsubsection{Pedagogical impact on students}

To analyze the pedagogical impact of the Laborem platform on the students, the averages of each group's marks in the face-to-face and distance learning sessions were analyzed. Table 5 shows that the impact was similar for group 1 and 2 . However, groups 2 and 3 , who had the same average grade in the face-to-face session, had a difference of 2.42 out of 10 in their average distance learning grade. Working in pairs was beneficial for the pedagogy during this remote work.

When analyzing the submitted reports, some students did not know which parameters to enter in order to have a coherent result (number of points too low, minimum number of frequency decades, signal frequency not adapted).

Thus, it seems necessary to assist the individual work in autonomy in order to avoid a student to be blocked or to try to give answers with worthless data. This need could be solved with the help of tags or safeguards (pop-up warnings).

Table 5. Comparison of average scores by group (on a 10-point scale).

\begin{tabular}{|l|l|l|l|}
\hline \hline Group & Average score in class & $\begin{array}{l}\text { Average score in distance } \\
\text { learning }\end{array}$ & $\begin{array}{r}\text { Difference between } \\
\text { distance and in-class } \\
\text { Group 1 }\end{array}$ \\
Group 2 & 4.61 & 3.57 & -1.04 \\
Group 3 & 5.23 & 4.45 & -0.79 \\
\hline
\end{tabular}

\section{RESULTS}

The Laborem open source platform developed at the IUT de Bayonne allows to quickly and simply adapt the need for distance learning, as well as to create new remote practical works. This tool is simple and cheap to set up for all those who have needs of remote practical work.

Whether it is from the student's point of view (motivation, feeling), from the use (regularity, frequency, duration) or from the pedagogical results (score, completion), our study has demonstrated the significant 
interest of working in pairs in the use of a remote laboratory, whereas the autonomous work in semirestricted access compared to the free access did not bring much added value.

\section{CONCLUSIONS}

Since remote laboratories must be easy to adapt and duplicate, Laborem's choice to use open software and hardware, standard protocols and low-cost hardware offers an interesting solution.

This advantage allowed us to quickly adapt the platform to the total or partial closure of French universities since March 2020.

The massive implementation of distance learning in the field of engineering sciences in response to economic issues is to be put in perspective with the interest of the student and the teacher. In order to maintain a high level of attention, it is necessary for the student to regularly attend classes that cannot be compensated by self-learning or by asynchronous online learning [9].

Our work now aims to improve and identify the limits of the massive use of remote practical work in order to address the problems of isolation of students.

Furthermore, our study focuses on the technology and pedagogical domains and leaves out the psychological domain. However, psychological research in cognitive sciences suggests that students' experiences and beliefs may be determined more by the characteristics of the interfaces than by the unbiased reality of the laboratory technology [10].

\section{REFERENCES}

[1] F. Luthon and B. Larroque, "LaboREM: A Remote Laboratory for Game-Like Training in Electronics," in IEEE Transactions on Learning Technologies, vol. 8, no. 3, pp. 311-321, 2014.

[2] A. Villar-Martínez, L. Rodríguez-Gil, I. Angulo, P. Orduña, J. García-Zubía and D. López-De-Ipiña, "Improving the Scalability and Replicability of Embedded Systems Remote Laboratories Through a Cost-Effective Architecture," in IEEE Access, vol. 7, pp. 164164-164185, 2019.

[3] B. Letowski, C. Lavayssière, B. Larroque, F. Luthon, "An open source remote laboratory network based on a ready to use solution: Laborem", ICERI2019 Proceedings, pp. 5726-5731, 2019.

[4] M. Schröder, "PyScada is an open source scada system that uses the Django framework as backend", 1 May 2021. Retrieved from: https://github.com/pyscada/PyScada

[5] C. Lavayssière, "PyScada-Laborem: Laborem extension to Pyscada", 1 May 2021. Retrieved from: https://github.com/clavay/PyScada-Laborem

[6] D. Lowe, "Integrating Reservations and Queuing in Remote Laboratory Scheduling," in IEEE Transactions on Learning Technologies, vol. 6, no. 1, pp. 73-84, Jan.-March 2013.

[7] L. A. Williams and R. R. Kessler, "The effects of "pair-pressure" and "pair-learning" on software engineering education," Thirteenth Conference on Software Engineering Education and Training, 2000, pp. 59-65.

[8] N. Salleh, E. Mendes and J. Grundy, "Empirical Studies of Pair Programming for CS/SE Teaching in Higher Education: A Systematic Literature Review," in IEEE Transactions on Software Engineering, vol. 37, no. 4, pp. 509-525, July-Aug. 2011.

[9] M. Sokele, T. Alajbeg and F. Brkić, "The impact of distance learning on student success for electrical engineering professional courses", 43rd International Convention on Information, Communication and Electronic Technology (MIPRO), pp. 617-621, 2020.

[10] Ma, Jing, et Jeffrey Nickerson. "Hands-on, simulated, and remote laboratories: A comparative literature review", in ACM Comput. Surv. 38, 2006. 